\title{
The Relationships of Extreme Precipitation and Temperature Events with Ethnographic Reports of Droughts and Floods in Nonindustrial Societies ${ }^{\mathscr{A}}$
}

\author{
B. S. FELZER \\ Earth and Environmental Sciences, Lehigh University, Bethlehem, Pennsylvania \\ CAROL R. EMBER \\ Human Relations Area Files, Yale University, New Haven, Connecticut \\ R. CHENG \\ Division of Geological and Planetary Sciences, California Institute of Technology, Pasadena, California \\ M. JIANG \\ Hawkesbury Institute for the Environment, Western Sydney University, Penrith, New South Wales, Australia \\ (Manuscript received 16 April 2019, in final form 17 October 2019)

\begin{abstract}
Our broad research goal is to understand how human societies adapt to natural hazards, such as droughts and floods, and how their social and cultural structures are shaped by these events. Here we develop meteorological data of extreme dry, wet, cold, and warm indices relative to 96 largely nonindustrial societies in the worldwide Standard Cross-Cultural Sample to explore how well the meteorological data can be used to hindcast ethnographically reported drought and flood events and the global patterns of extremes. We find that the drought indices that are best at hindcasting ethnographically reported droughts [precipitation minus evaporation $(P-E)$ measures] also tend to overpredict the number of droughts, and therefore we propose a combination of these two indices plus the PDSI as an optimal approach. Some wet precipitation indices (R10S and R20S) are more effective at hindcasting ethnographically reported floods than others. We also calculate the predictability of those extreme indices and use factor analysis to reduce the number of variables so as to discern global patterns. This work highlights the ability to use extreme meteorological indices to fill in gaps in ethnographic records; in the future, this may help us to determine relationships between extreme events and societal response over longer time scales than are otherwise available.
\end{abstract}

\section{Introduction}

With accelerating climate change, there is increased urgency to study the effects of natural hazards, such as drought and flood, on social and cultural groups to address questions such as the following: Do natural hazards, particularly those that cause severe destruction of food supplies, increase the likelihood of warfare

Supplemental information related to this paper is available at the Journals Online website: https://doi.org/10.1175/WCAS-D-190045.s1.

Corresponding author: B. S. Felzer, bsf208@lehigh.edu and other forms of violence (Ember and Ember 1992a; Ember et al. 2013)? Do people living in hazard-prone environments have special adaptations to such environments, such as more customary sharing (Ember et al. 2018), more communal property rights, preference for strong rules and norms, more subsistence diversity, more exclusionary leadership, or different political systems? Many historical studies have been undertaken, particularly regarding violence (e.g., Kang 2000; Zhang et al. 2007, 2011). But most societies in the world lack extensive written histories. If we want to expand our understanding of adaptation to hazards, it is prudent to study societies at different levels of cultural complexity as well as societies with different 


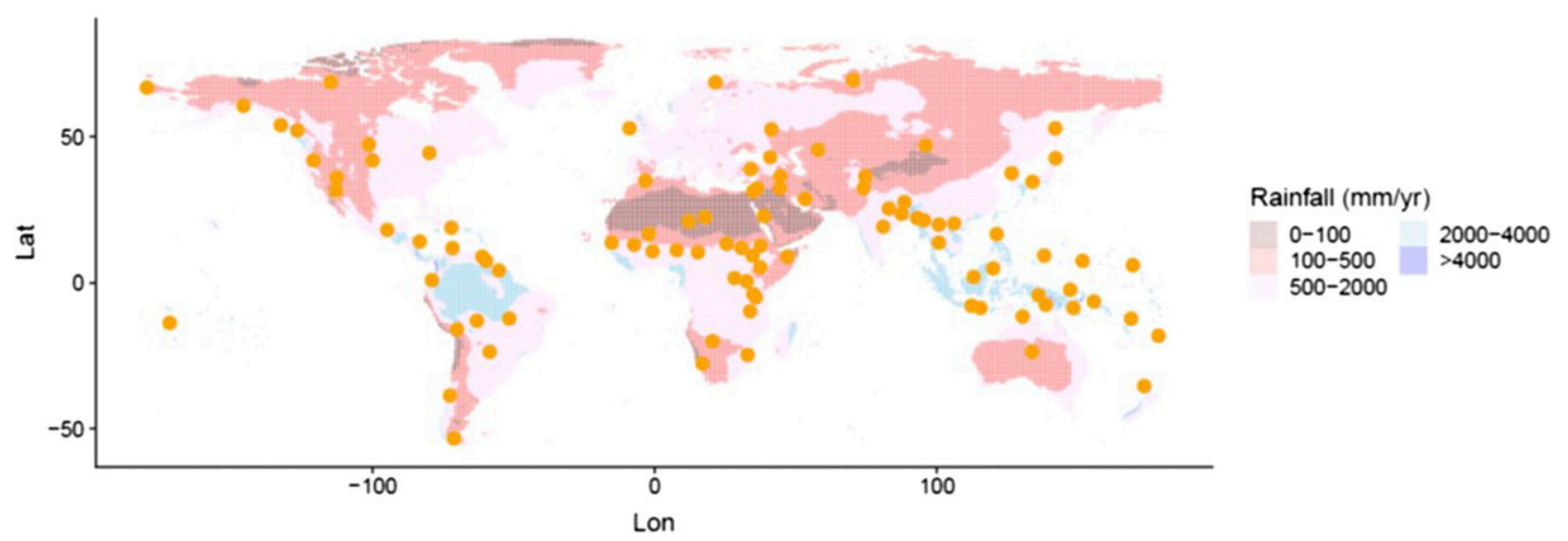

FIG. 1. Location of the 96 SCCS sites used in this study.

forms of subsistence. To do this research, however, we need data on cultural practices as well as hazards. Ethnography is the main source of data on societies that lack written history. Ethnographers, who generally live with and intensively study cultural communities during a year or more of fieldwork, also try to cover aspects of history that they gather from interviews with elders, accounts of travelers and other earlier observers, and reports from archival sources and newspapers, when available. In this way, ethnographers, in the course of writing comprehensive descriptions of social and cultural life usually describe current and past events, including records of previous hazards.

Using ethnographic data, our larger project is examining how natural hazards that disrupt food supply (such as droughts or floods) may transform cultural practices. We are testing hypotheses on a subset of a worldwide cross-cultural sample of 186 societies [the "Standard Cross-Cultural Sample" (SCCS); Murdock and White 1969]. Although we would have liked to have used the whole SCCS sample, as explained further in the methods section, only about one-half of the SCCS societies were reliably coded on frequency of natural hazards (Ember and Ember 1992a,b), and therefore we limited our potential number of cases to those cases (Fig. 1). Our goal was to find alternative measures of drought and flood so that we could ultimately study the remaining societies in the 186-case sample. Therefore, our team, consisting of climatologists and anthropologists, has sought to supplement our ethnographically described hazard data with weather data. The advantage of weather data, assuming nearby weather stations, is that it usually can be found for a relatively long and continuous period of time from the start of the twentieth century or even back to the nineteenth century, whereas ethnographers may only have information for a relatively short period of time when they or other outside observers were present to record events. But critical to our use of weather data is how well these different types of data correspond. The main research questions we address in this paper are as follows: How well do historic weather data hindcast ethnographically reported droughts and floods, and what extreme indices can we use for this purpose? As we will see, historic weather data only partially correspond to ethnographer-reported data. We also ask the following: What are the geographic patterns of the weather data extreme indices based on the ethnographic sites? Can we relate these patterns to rainfall and temperature and their variability? Are there geographic patterns in predictability of extremes, and how do these relate to rainfall and temperature and their variability?

\section{Data and methods}

The widely used SCCS of 186 mostly nonindustrial societies distributed around the world was constructed to represent the world's known and well-described cultures, and to maximize historical independence of cases (Murdock and White 1969). One society was chosen from each of 186 geographic culture areas. The main reason for choosing this sample was that the most important independent variable for our larger projectthreat of weather or pest disasters that severely disrupted food supplies (hereinafter hazards) -was previously coded for the Ember and Ember (1992a,b) study on predictors of warfare. Although we did not use the Embers's four-point ordinal (ranked) scale of hazard frequency in this study, we wanted to start with cases that met two criteria: 1) the coders were able to arrive at a resolved score after discussing any disagreements, and 2) the cases with higher initial disagreements 
between the coders were eliminated (on a reliability scale ranging from 1 to 8 , where 1 is no disagreement, we eliminated reliability scores of 6-8; see Ember and Ember 1992b, p. 182). There were 98 societies from the 186 that met these criteria, but we also eliminated Hebrews (621 BCE) and Babylonians (1750 BCE) because their time frames were too ancient, making a total of 96 societies for this study.

The SCCS does not contain ethnographic materialsrather, it contains pointers to ethnographic texts that match a specified time and place focus when the main ethnographer did his or her work - the time focus is referred to as the "ethnographic present." The time foci mostly range from the 1800 s to 1965 , with a few earlier focal dates. For this study, our ethnographic material was drawn largely from eHRAF World Cultures (https://hraf.yale.edu/products/ehraf-world-cultures/), an online database containing ethnographic documents on over 320 societies. Each document is subject indexed to the paragraph level to facilitate data retrieval. The database now contains ethnographic materials for most of the societies in the Standard Cross-Cultural Sample. For those SCCS societies not yet in eHRAF World Cultures, we obtained the main focal documents from Yale University and other libraries.

We had two main aims: 1) to develop climate/weather quantitative measures (for drought and/or flood) that we hoped would be more precise measures for these 96 cases coded from ethnographic texts and 2) to use these measures of drought and flood for the rest of the SCCS sample that had less reliable hazard scores. To further these aims we concentrated our development of measures on those societies from the 96 for which we had precise yearly dates given by ethnographers for droughts and/or floods. To find precise dates, we had our assistants do the following: 1) Review the Embers' coding notes (courtesy of author C. Ember) to look for precise dates of disasters if available and 2) search all ethnographic sources in eHRAF World Cultures (within and outside the ethnographic present) to look for additional dates. When using eHRAF World Cultures, the coders searched used "Advanced Search" to look for the subject categories "Disaster" and/or "Water Supply" and/or the keywords "drought*," "flood*," "monsoon*," "hurricane*," and "cyclone*," where the asterisk is a wild card that indicates any set of characters that contain the opening characters. For those SCCS societies not yet in eHRAF World Cultures, we obtained ethnographic documents listed in the White (1989) bibliography.

To effectively gather appropriate weather data (see section $2 \mathrm{~b}$ below) we also needed a focal latitude and longitude for each SCCS case. The SCCS sample gives a rounded latitude and longitude for each case. If the ethnographer focused on a community, the latitude and longitude might be specific to that community. If the ethnographer was generalizing to the whole society (often the case with smaller societies), a central latitude and longitude was computed from maps and/or latitude and longitude ranges given by ethnographers. However, because we also wanted to identify the closest appropriate weather station, we examined maps within the ethnography and consulted Google Earth to try to get a more precise location that would match the topography mentioned in the ethnography. This was especially important in mountainous or coastal regions where major differences in topography might be adjacent. Weather stations that were not within $2^{\circ} \times 2^{\circ}$ of the SCCS focal latitude and longitude were excluded.

There are 17 societies for which we have precise drought dates and 18 for which we have precise flood dates. Table 1 gives a brief overview of the societies in our study, including the SCCS ID, SCCS society name, SCCS focal date, eHRAF World Cultures society name, primary subsistence, and geographical region. More detail on drought and flood dates with ethnographic supporting statements can be found in Tables S1a and $\mathrm{S} 1 \mathrm{~b}$ in the online supplemental material.

\section{a. Extreme indices}

To develop a set of extreme indices to represent droughts and the potential for floods, we have chosen from the 27 core indices developed at the Expert Team on Climate Change Detection and Indices (Karl et al. 1999; Peterson et al. 2001). These indices are based on daily precipitation and minimum and maximum temperature and are derived from weather station data. We also developed two new dry indices (R01PS and R05PS) analogous to the R95PS and R99PS wet indices (Table 3). Besides these indices, for droughts we also examined the widely used Palmer drought severity index (PDSI) (described below) and some precipitationminus-evaporation indices, which we developed from globally gridded datasets.

\section{b. Weather station data}

Daily precipitation, minimum temperature, and maximum temperature data were obtained from weather stations in the Global Historical Climatology Network (GHCN; Menne et al. 2012). In most cases, the weather stations started to record these variables in the 1950s, while our ethnographic floods occurred prior to these instrumental measurements. Because there are significant gaps in the daily data, we developed a simple gapfilling procedure. For precipitation, the nine GHCN stations nearest the SCCS latitude and longitude 
TABLE 1. SCCS cases used in this study. Note that the Primary subsistence type (https://ehrafworldcultures.yale.edu/webhelp/ \#Subsistence/subsistence.html) follows the classification from eHRAF World Cultures, as does the main geographic region for those societies in eHRAF World Cultures; the Ethnographic Atlas (via https://d-place.org/contributions/EA) provided subsistence information for those SCCS societies that are not yet in eHRAF World Cultures.

\begin{tabular}{|c|c|c|c|c|c|}
\hline SCCS ID & $\begin{array}{l}\text { SCCS society } \\
\text { name }\end{array}$ & SCCS focal date & $\begin{array}{l}\text { eHRAF World Cultures } \\
\text { society name }\end{array}$ & Primary subsistence & $\begin{array}{l}\text { Geographical } \\
\text { region }\end{array}$ \\
\hline 1 & Nama & 1860 & Khoi & Other subsistence combinations & Africa \\
\hline 2 & !Kung & 1950 & San & Hunter-gatherers & Africa \\
\hline 8 & Nyakyusa & 1934 & Nyakyusa and Ngonde & Intensive agriculturalists & Africa \\
\hline 9 & Hadza & 1930 & Hadza & Hunter-gatherers & Africa \\
\hline 12 & Ganda & 1875 & Ganda & Intensive agriculturalists & Africa \\
\hline 13 & Mbuti & 1950 & Mbuti & Hunter-gatherers & Africa \\
\hline 21 & Wolof & 1950 & Wolof & Horticulturalists & Africa \\
\hline 22 & Bambara & 1902 & Bambara & Agro-pastoralists & Africa \\
\hline 23 & Tallensi & 1934 & Tallensi & Intensive agriculturalists & Africa \\
\hline 24 & Songhai & 1940 & Songhai & Agro-pastoralists & Africa \\
\hline 25 & Fulani & 1951 & & Pastoralists & Africa \\
\hline 26 & Hausa & 1900 & Hausa & Intensive agriculturalists & Africa \\
\hline 27 & Massa & 1910 & & Other subsistence combinations & Africa \\
\hline 29 & Fur & 1880 & & Intensive agriculturalists & Africa \\
\hline 30 & Otoro & 1930 & Nuba & Intensive agriculturalists & Africa \\
\hline 32 & Mao & 1939 & Mao & Horticulturalists & Africa \\
\hline 34 & Masai & 1900 & Maasai & Pastoralists & Africa \\
\hline 35 & Konso & 1935 & Konso & Intensive agriculturalists & Africa \\
\hline 36 & Somali & 1900 & Somali & Pastoralists & Africa \\
\hline 37 & Amhara & 1953 & Amhara & Intensive agriculturalists & Africa \\
\hline 39 & Barabra & 1900 & & Intensive agriculturalists & Africa \\
\hline 40 & Teda & 1950 & Teda & Agro-pastoralists & Africa \\
\hline 42 & Riffians & 1926 & Berbers of Morocco & Agro-pastoralists & Africa \\
\hline 43 & Egyptians & 1950 & Fellahin & Intensive agriculturalists & Africa \\
\hline 44 & Hebrews & -621 & & Other subsistence combinations & Middle East \\
\hline 45 & Babylonians & -1750 & Babylonians & Intensive agriculturalists & Middle East \\
\hline 46 & Rwala Bedouin & 1913 & Rwala Bedouin & Pastoralists & Middle East \\
\hline 47 & Turks & 1950 & Turks & Intensive agriculturalists & Middle East \\
\hline 51 & Irish & 1932 & Rural Irish & Agro-pastoralists & Europe \\
\hline 52 & Lapps & 1950 & Saami & Pastoralists & Europe \\
\hline 53 & Yurak Samoyed & 1894 & Samoyed & Primarily hunter-gatherers & Asia \\
\hline 54 & Russians & 1955 & & Intensive agriculturalists & Eurasia \\
\hline 55 & Abkhaz & 1880 & Abkhazians & Pastoralists & Asia \\
\hline 57 & Kurd & 1951 & Kurds & Agro-pastoralists & Middle East \\
\hline 58 & Basseri & 1958 & Basseri & Pastoralists & Middle East \\
\hline 59 & Punjabi & 1950 & & Intensive agriculturalists & Asia \\
\hline 60 & Gond & 1938 & Gond & Agro-pastoralists & Asia \\
\hline 62 & Santal & 1940 & Santal & Intensive agriculturalists & Asia \\
\hline 63 & Uttar Pradesh & 1945 & Uttar Pradesh & Intensive agriculturalists & Asia \\
\hline 64 & Burusho & 1934 & Burusho & Intensive agriculturalists & Asia \\
\hline 65 & Kazak & 1885 & Kazakh & Pastoralists & Asia \\
\hline 66 & Khalka Mongols & 1920 & Mongolia & Pastoralists & Asia \\
\hline 68 & Lepcha & 1937 & Lepcha & Intensive agriculturalists & Asia \\
\hline 70 & Lakher & 1930 & & Horticulturalists & Asia \\
\hline 71 & Burmese & 1965 & Burmese & Intensive agriculturalists & Asia \\
\hline 72 & Lamet & 1940 & Rmeet & Agro-pastoralists & Asia \\
\hline 73 & Vietnamese & 1930 & Vietnamese & Intensive agriculturalists & Asia \\
\hline 76 & Siamese & 1955 & Central Thai & Intensive agriculturalists & Asia \\
\hline 83 & Javanese & 1954 & Javanese & Intensive agriculturalists & Asia \\
\hline 84 & Balinese & 1958 & Balinese & Intensive agriculturalists & Asia \\
\hline 85 & Iban & 1950 & Iban & Horticulturalists & Asia \\
\hline 86 & Badjau & 1963 & & Primarily hunter-gatherers & Asia \\
\hline 90 & Tiwi & 1929 & Tiwi & Hunter-gatherers & Oceania \\
\hline 91 & Aranda & 1896 & Aranda & Hunter-gatherers & Oceania \\
\hline
\end{tabular}


TABLE 1. (Continued)

\begin{tabular}{|c|c|c|c|c|c|}
\hline SCCS ID & $\begin{array}{l}\text { SCCS society } \\
\text { name }\end{array}$ & SCCS focal date & $\begin{array}{l}\text { eHRAF World Cultures } \\
\text { society name }\end{array}$ & Primary subsistence & $\begin{array}{l}\text { Geographical } \\
\text { region }\end{array}$ \\
\hline 92 & Orokaiva & 1925 & Orokaiva & Other subsistence combinations & Oceania \\
\hline 93 & Kimam & 1960 & Kimam & Intensive agriculturalists & Oceania \\
\hline 94 & Kapauku & 1955 & Kapauku & Horticulturalists & Oceania \\
\hline 96 & Manus & 1929 & Manus & Hunter-gatherers & Oceania \\
\hline 99 & Siuai & 1939 & Siwai & Agro-pastoralists & Oceania \\
\hline 100 & Tikopia & 1930 & Tikopia & Other subsistence combinations & Oceania \\
\hline 102 & Mbau Fijians & 1840 & & Primarily hunter-gatherers & Oceania \\
\hline 104 & Maori & 1820 & Maori & Primarily hunter-gatherers & Oceania \\
\hline 106 & Samoans & 1829 & Samoa & Horticulturalists & Oceania \\
\hline 108 & Marshallese & 1900 & Marshallese & Primarily hunter-gatherers & Oceania \\
\hline 109 & Trukese & 1947 & Chuuk & Other subsistence combinations & Oceania \\
\hline 110 & Yapese & 1910 & Yapese & Other subsistence combinations & Oceania \\
\hline 112 & Ifugao & 1910 & Ifugao & Intensive agriculturalists & Asia \\
\hline 116 & Koreans & 1947 & Korea & Intensive agriculturalists & Asia \\
\hline 117 & Japanese & 1950 & Okayama & Intensive agriculturalists & Asia \\
\hline 118 & Ainu & 1880 & Ainu & Hunter-gatherers & Asia \\
\hline 119 & Gilyak & 1890 & Nivkh & Hunter-gatherers & Asia \\
\hline 121 & Chukchee & 1900 & Chukchee & Other subsistence combinations & Asia \\
\hline 124 & Copper Eskimo & 1915 & Copper Inuit & Hunter-gatherers & North America \\
\hline 130 & Eyak & 1890 & & Hunter-gatherers & North America \\
\hline 131 & Haida & 1875 & Haida & Hunter-gatherers & North America \\
\hline 132 & Bellacoola & 1880 & Nuxalk & Hunter-gatherers & North America \\
\hline 138 & Klamath & 1860 & Klamath & Hunter-gatherers & North America \\
\hline 141 & Hidatsa & 1836 & & Intensive agriculturalists & North America \\
\hline 142 & Pawnee & 1867 & Pawnee & Other subsistence combinations & North America \\
\hline 144 & Huron & 1634 & & Other subsistence combinations & North America \\
\hline 150 & Havasupai & 1918 & Havasupai & Other & North America \\
\hline 151 & Papago & 1910 & O'odham & Other subsistence combinations & North America \\
\hline 154 & Popoluca & 1940 & & Horticulturalists & $\begin{array}{l}\text { Middle America and } \\
\text { the Caribbean }\end{array}$ \\
\hline 156 & Miskito & 1921 & Miskito & Primarily hunter-gatherers & $\begin{array}{l}\text { Middle America and } \\
\text { the Caribbean }\end{array}$ \\
\hline 159 & Goajiro & 1947 & Goajiro & Pastoralists & South America \\
\hline 160 & Haitians & 1935 & Haitians & Intensive agriculturalists & $\begin{array}{l}\text { Middle America and } \\
\text { the Caribbean }\end{array}$ \\
\hline 162 & Warrau & 1935 & Warao & Hunter-gatherers & South America \\
\hline 164 & Barama Carib & 1932 & Barama River Carib & Primarily hunter-gatherers & South America \\
\hline 165 & Saramacca & 1928 & Saramaka & Other subsistence combinations & South America \\
\hline 168 & Cayapa & 1908 & Chachi & Other subsistence combinations & South America \\
\hline 172 & Aymara & 1940 & Aymara & Horticulturalists & South America \\
\hline 173 & Siriono & 1942 & Siriono & Hunter-gatherers & South America \\
\hline 179 & Shavante & 1958 & & Primarily hunter-gatherers & South America \\
\hline 182 & Lengua & 1889 & & Hunter-gatherers & South America \\
\hline 184 & Mapuche & 1950 & Mapuche & Intensive agriculturalists & South America \\
\hline 186 & Yahgan & 1865 & Yahgan & Hunter-gatherers & South America \\
\hline
\end{tabular}

(see above) were chosen, while for minimum and maximum temperature, the four closest stations were chosen. The weather station closest to the SCCS site was the primary station to be gap filled based on the other chosen stations. Only periods where at least two of the stations shared common temporal coverage were used, and those stations with greater than $50 \%$ missing values were ignored. A linear relationship was used for commonly shared periods to fill in the gaps. For gaps where none of the four or nine stations had data, the gap was filled with the corresponding monthly/seasonal/annual data for the entire dataset of the primary station. All stations with less than 10 years of data were eliminated.

\section{c. Gridded data}

The monthly temperature $T$, precipitation $P$, and Penman-Monteith potential evapotranspiration (PET_pm) data were downloaded from the Climatic Research Unit (CRU) at the University of East Anglia, United Kingdom, 
which ranges from 1901 to 2014 with a spatial resolution of $0.5^{\circ} \times 0.5^{\circ}(\mathrm{CRU} 3.23)$ (Harris et al. 2014). We also used the CRU data from 1901 to 2009 (van der Schrier et al. 2013) to construct the PDSI. ${ }^{1}$ The variables $T, P$, and PET_pm were used to calculate the precipitationminus-evaporation $(P-E)$ drought index, which describes the deficit of soil moisture.

PDSI (Alley 1984) is derived from a two-layer soil moisture model accounting for antecedent moisture conditions (AMC) (Palmer 1965). Larger negative values relate to more severe droughts, such that $<-2.0$ is moderate drought, $<-3.0$ is severe drought, and -4.0 is extreme drought (van der Schrier et al. 2013). For each of the 96 SCCS sites, we determined the number of three or more nonconsecutive months within the growing season of each society for which the PDSI value was less than various thresholds $(0,-0.5,-1$, etc. $)$ (Table 2).

The $P-E$ index was developed by Chang et al. (2018) to describe meteorological droughts. It does not incorporate the AMC like PDSI. The $P-E$ index defines the soil moisture deficit as a function of $P$ and PET:

$$
P-E \text { index }=\frac{P-\text { PET }}{\operatorname{Max}(P-\mathrm{PET})},
$$

in which every site is normalized by the maximum of monthly $P$ - PET over all the years (1901-2009) at a given month. The lower the index value is, the drier is the soil. We developed two versions of the $P-E$ index, one derived from the Thornthwaite (Willmott et al. 1985) PET ( $P-E_{-}$th) and the other derived from the Penman-Monteith PET ( $P-E \_$pm).

For each of the 96 SCCS sites, we ranked the $P-E$ index values in descending order and determined the values for specified percentile thresholds (i.e., 60\%, $70 \%, 80 \%, 85 \%, 90 \%, 95 \%$, and $98 \%$; Table 2), and then we determined the number of three or more nonconsecutive months within the growing season for each year for which the $P-E$ value was below that threshold. Use of consecutive months yielded too few drought years. Finally, we combined the three indices $\left(P-E_{-}\right.$th, $P-E \_$pm, and PDSI) for each year at each site to provide a drought index (Drought_Combined) in which drought status was only given if all three indices showed drought.

We also developed three dry indices (R05PS, R01PS, and CDD; see Table 3 for definitions) based on daily precipitation data from weather stations, analogous to

\footnotetext{
${ }^{1}$ The ethnographic time periods largely overlap with, but are not identical to, these years.
}

TABLE 2. Drought indices based on gridded CRU data, with their time and the thresholds for defining droughts.

\begin{tabular}{lcl}
\hline \hline \multicolumn{1}{c}{ Drought index } & Time & \multicolumn{1}{c}{ Threshold } \\
\hline PDSI & $1901-2009$ & Numeric values \\
$P-E \_$th & $1901-2014$ & Percentiles \\
$P-E \_p m$ & $1901-2014$ & Percentiles \\
Drought_Combined & $1901-2009$ & As above, for both indices \\
\hline
\end{tabular}

the extreme precipitation indices used for wet conditions below. The R05PS and R01PS measures are the sum of daily precipitation less than the fifth and first percentile for the season, respectively, and so represent the amount of precipitation on low precipitation days. The CDD is the number of continuous days of no precipitation normalized by the total number of days.

\section{d. Precipitation indices}

Ten extreme precipitation indices (Jiang et al. 2016) and four other indices were derived from the daily precipitation of GHCN weather stations (Table 3). For each of these precipitation indices, we derived the mean and standard deviation (e.g., $>1 \sigma$ or $2 \sigma$ ) in each season (i.e., December-February, March-May, June-August, and September-November) for each year. The mean plus 1 standard deviation represented the threshold value for each of the indices. The consecutive-day indices (CWD, CDD; Table 3) for consecutive wet and dry days, respectively, were based on growing seasons for each society, as well as the month prior to and following the growing season. This was done for the four most abundant crops at each SCCS site, where their corresponding growing season was defined based on the Center for Sustainability and the Global Environment (SAGE) Crop Calendar dataset (Sacks et al. 2010). For hunter-gatherer or pastoral societies, we instead calculated these indices for each season (like the other indices). We also computed a measure of variation in precipitation, both intra-annually, based on monthly precipitation, and interannually, based on total annual precipitation, that corrects for the mean value to make societal differences in standard deviations comparable (coefficient of variation; see Abdi 2010).

\section{e. Temperature indices}

Besides drought and flooding events, crops are also subject to stress due to extreme cold or hot spells. We therefore used the daily minimum and maximum temperatures to calculate two cold-spell and two hot-spell indices (Table 4). While we did not have ethnographic data to directly relate to cold or hot extremes, we are 
TABLE 3. Indices derived from daily precipitation from GHCN weather stations.

\begin{tabular}{|c|c|c|}
\hline Index & Definition & Wet/Dry \\
\hline R10S & No. of days within a season with precipitation $>10 \mathrm{~mm} \mathrm{day}^{-1}$ & Wet \\
\hline $\mathrm{R} 20 \mathrm{~S}$ & No. of days within a season with precipitation $>20 \mathrm{~mm} \mathrm{day}^{-1}$ & Wet \\
\hline R95PS & Sum of daily precipitation $>95$ th percentile for the season & Wet \\
\hline R99PS & Sum of daily precipitation $>99$ th percentile for the season & Wet \\
\hline RX1S & Seasonal max 1-day precipitation & Wet \\
\hline RX5S & Seasonal max 5-day precipitation & Wet \\
\hline SDIIS $^{\mathrm{a}}$ & $\begin{array}{l}\text { Total precipitation divided by total no. of days with } \\
\text { precipitation }>1 \mathrm{~mm}^{-1} \text { day }^{-1}\end{array}$ & Wet \\
\hline CWD & No. of continuous rainy days/total no. of days & Wet \\
\hline R05PS & Sum of daily precipitation $<$ fifth percentile for the season & Dry \\
\hline R01PS & Sum of daily precipitation $<$ first percentile for the season & Dry \\
\hline CDD & No. of continuous no-precipitation days/total no. of days & Dry \\
\hline PRCPTOTS $^{\mathrm{a}}$ & Total seasonal precipitation & Wet \\
\hline CV_Inter ${ }^{\mathrm{a}}$ & Coef of variation on basis of interannual & \\
\hline CV_Intra ${ }^{a}$ & Coef of variation on basis of intrannual & \\
\hline
\end{tabular}

${ }^{\mathrm{a}}$ Nonextreme index.

using temperature extreme data in subsequent analysis relative to ethnographic data.

\section{f. Capture rates for droughts and floods}

We evaluated the wet and dry thresholds by true positives $(T+)$ and true negatives $(T-)$ :

$$
\begin{aligned}
& T+=\frac{\text { the number of true droughts that are captured }}{\text { the number of true drought years in ethnographic data }}, \text { and } \\
& T-=\frac{\text { the number of years without drought that are captured }}{\text { the number of years without droughts in the ethnographic record }} .
\end{aligned}
$$

We considered the optimal threshold for drought societies to be the one with the highest sum of $T+$ and $T-$ (given at least a $T+$ of greater than 0 ) at each site since we are trying to predict both the presence and absence of drought. (Note that a perfect match would be one where both are equal to 1 , indicating complete predictability.) We made the decision to exclude cases with $0 T+$ even with large $T$ - because the threshold should at least be able to capture some extreme events. The technique is illustrated in Fig. 2 for the PDSI drought index. The optimal threshold for each biome was determined from the mean of the optimal threshold from the 17 drought societies with the same biome (two societies did not match up to gridded data years). The optimal thresholds can then be applied to the other societies without recorded events. For the flood societies for which the thresholds are based on the mean plus 1 standard deviation within the seasons of the growing season (Fig. 3), we also calculated the $T+$ and $T-$ as a measure of the optimal threshold. Of the 18 flood societies, only 7 had overlapping years between the

TABLE 4. Indices derived from daily minimum temperature (Tmin) and maximum temperature (Tmax) from GHCN weather stations.

\begin{tabular}{llc}
\hline \hline Index & Definition & Cold/hot \\
\hline FD & No. of frost days: no. of days on which Tmin $<0^{\circ} \mathrm{C}$ & Cold \\
CSDI & Cold-spell duration index: no. of consecutive days with Tmin $<10$ th & Cold \\
percentile (based on entire time period at each site) $/$ total no. of days & Cold \\
Tmin & Min daily temperature & Warm \\
SU & No. of summer days: no. of days on which Tmax $>25^{\circ} \mathrm{C}$ & Warm \\
WSDI & Warm-spell duration index: no. of consecutive days with Tmax $>90$ th & Warm \\
Tmax & Max daily temperature & \\
\hline
\end{tabular}




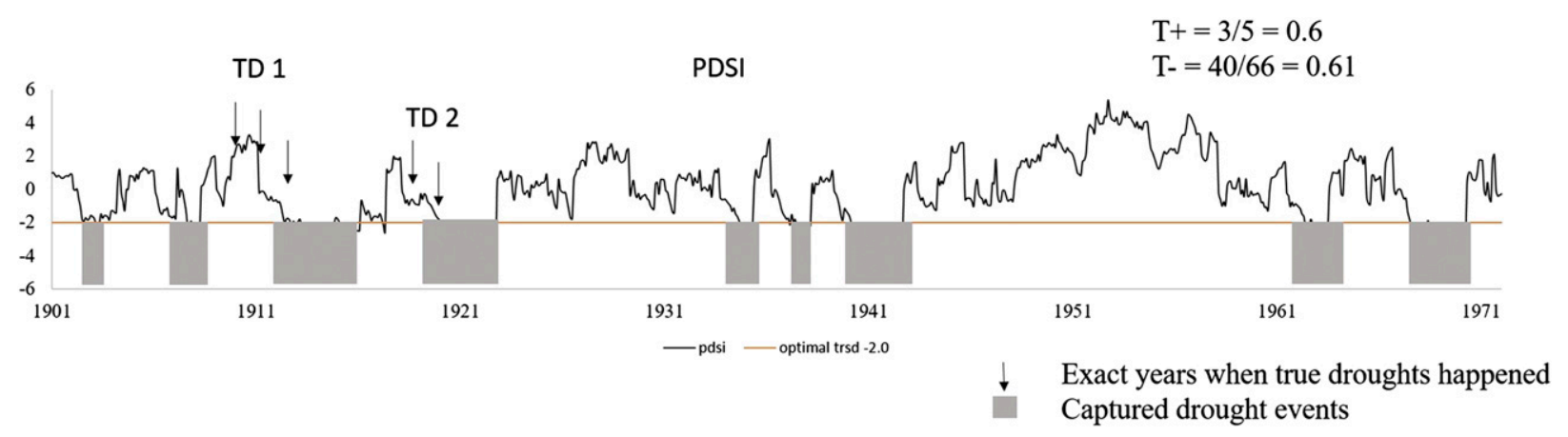

FIG. 2. Drought example: PDSI for Central Thai society, illustrating true positives $(T+)$, true negatives $(T-)$, and true drought (TD) (as recorded by the ethnographers), based on optimal threshold for the society (colored horizontal line) for three or more nonconsecutive months during the growing season, which is January-December for this site. Captured droughts, when indices are below threshold, are denoted in gray. Multiyear ethnographic droughts are classified as single drought events. The ethnographic record is from 1831 to 1971; the PDSI goes from 1901 to 2009. The period of overlap between the ethnographic records and drought indices is shown. In this example case, there are two TD events in the SCCS record, with the TD1 event lasting $3 \mathrm{yr}$ and the TD2 event lasting $2 \mathrm{yr}$. In comparison, nine droughts were detected in the PDSI record for the period of overlap. PDSI has captured the SCCS-reported TD events, but the captured droughts did not match perfectly to the drought-year events $(T+=0.6)$. The true-negative value is relatively comparable to the truepositive value $(T-=0.61)$.

GHCN weather station data and the period of ethnographic record.

\section{g. Other measures (in the online supplementary material)}

To determine if the drought measures really do correspond to food shortages, we compared them with recorded crop yield where available, as well as historically recorded droughts. Crop yield data are from the U.S. Department of Agriculture (USDA; USDA 2019), and disaster history data are from the Lehigh Valley in Pennsylvania (Pennsylvania Emergency Management Agency; https:// www.pema.pa.gov/responseandrecovery/Disaster-Assistance/ Pages/PA-Disaster-History.aspx), and Oregon (NCEI 2019), which were chosen as case study sites. These were two sites available in the disaster history dataset.

To better understand how extreme precipitation related to flooding, we used volumetric soil moisture (VSM) from the Terrestrial Ecosystem Model (TEMHydro; Felzer et al. 2011), because extreme precipitation only leads to flooding if the soil is saturated. We ran a global TEM-Hydro simulation to produce gridded VSM. We used these data to eliminate extreme precipitation events that occur in years when the soil is relatively dry, defined as VSM values less than the mean minus 1 standard deviation.

Predictability, based on the Colwell index (Colwell 1974), was calculated for all of the indices based on the GHCN weather station data, to assess whether it is the predictability of extremes rather than the extremes themselves that actually affect societal response (section SI2 in the online supplemental material). Factor analysis was used to reduce the dimensions of the large number of variables to determine geographic patterns of wet, dry, and cold extremes as well as the predictability of wet and dry extremes at each of the SCCS sites. Details on this procedure are in the online supplemental material (section SI3).

\section{Results}

The $T+$ and $T-$ measures are used to compare both drought and flood indices to determine how well they can be used to hindcast ethnographic droughts and floods. Across all SCCS sites, the $P-E$ and PDSI indices have higher $T+$ than $T-$, whereas the combined drought index is the inverse (Fig. 4a). The precipitation extreme-based dry indices (R01, R05, and CDD) were not included because in most sites there were no recorded droughts during the limited years of available weather data. On average, $P-E_{-}$pm reported the highest $T+$ [mean $=0.8$; standard error $(\mathrm{SE})=0.07]$, but this is accompanied by the lowest $T$ - rate (mean = $0.5 ; \mathrm{SE}=0.08)$. In comparison, the PDSI reported a lower $T+$ and a higher variability in $T+$ (mean $=0.6$; $\mathrm{SE}=0.1)$. Both $P-E$ indices reported the lowest $T-$ $($ mean $=0.5)$. The combined drought index was worse in $T+$ and better in $T$ - than any of the individual indices (Fig. 4b). Since the drought thresholds are optimized individually for each society, we also classified the drought societies into Köppen-Geiger climate classes (biomes) (Köppen and Geiger 1936) to provide a more general method of determining thresholds (Fig. S1 of the online supplemental material). We also compared the drought indices at selected sites with known crop yields to demonstrate that droughts usually, but not 


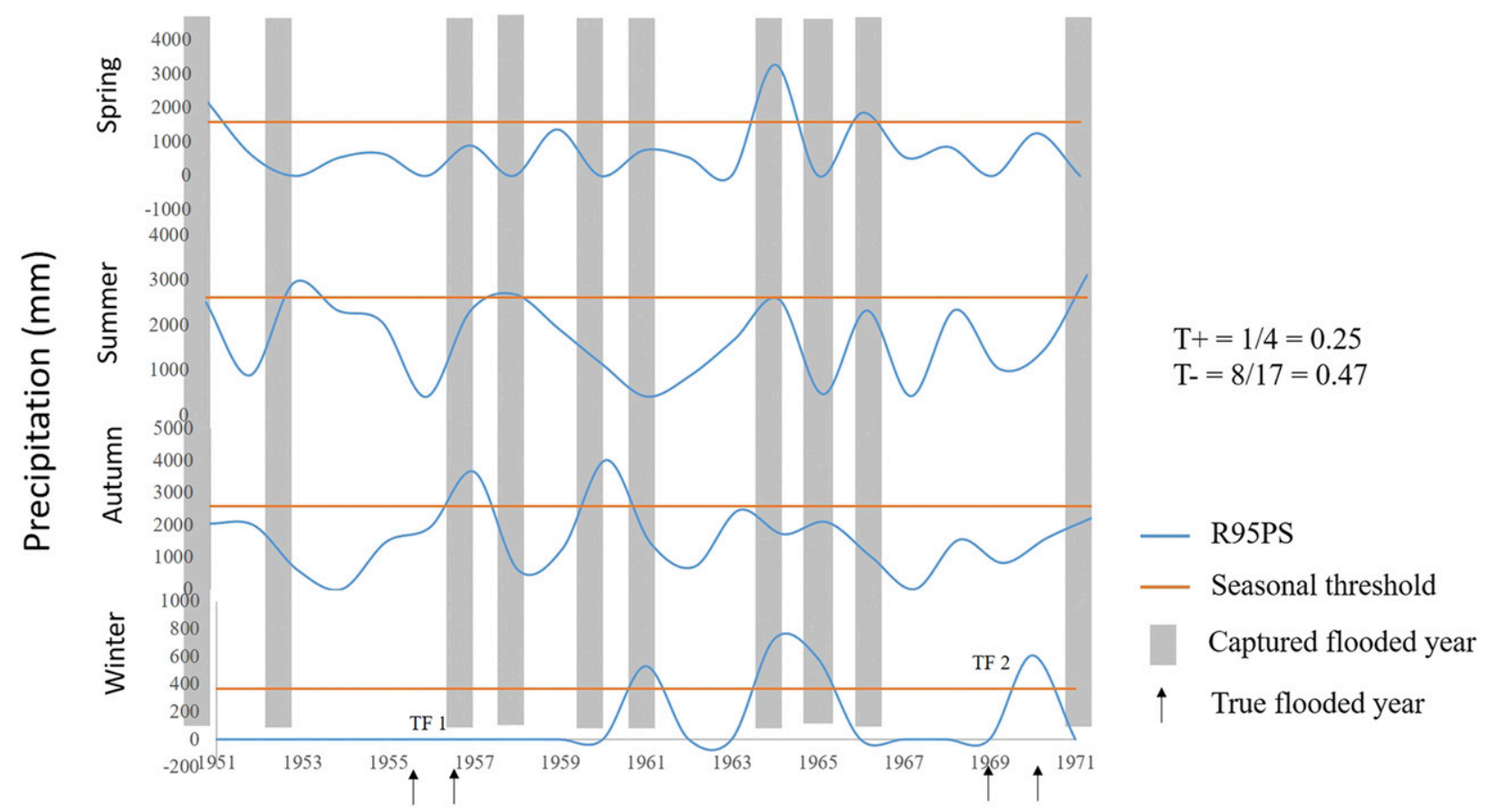

FIG. 3. Potential flood example for the Central Thai site, illustrating $T+, T-$, and recorded floods for the extreme precipitation index of 95th percentile of seasonal precipitation (R95PS). From top to bottom, the plots are the R95PS value (blue lines) in spring (March-May), summer (June-August), autumn (September-November), and winter (December-February). The orange horizontal lines are the threshold of 1 standard deviation above mean in each season. If the R95PS of a given year is above the threshold in any season, that year is defined as a flooded year (gray shaded). The ethnographic record is from 1831 to 1971, and the climate data are from 1951 to 2015 . Only the period of overlap is shown. Ethnographic floods are recorded in 1956, 1957, 1969, and 1970 (solid arrows), meaning two true-flood events (TF1 and TF2). This example illustrates that if the index is above the standard-deviation-based threshold for any one of the four seasons, that year is classified as a potential flooding event. Both the thresholds and indices are different for each season. In this case, there are 10 potential flooding events reported by the R95PS index, although SCCS record only indicated four flooding years. Among the four flooding years, the R95PS index captured only one event, and therefore $T+$ is 0.25 .

always, correspond to low crop yields (Fig. S2 of the online supplemental material).

Synthesizing potential floods for all of the sites shows reduced overall $T+$ and slightly higher $T$ - as compared with those for droughts (Fig. 5 and supplemental Fig. S3). Many indices have zero $T+$ for some sites (e.g., sites 2, 8, 76, and 117 under RX1S and R99P), indicating that these indices may not be good indicators for flooding events. Overall, the best measure of true-flooding events (i.e., floods reported by ethnographers) is R20S and R10S - the number of days on which daily rainfall exceeds 20 or $10 \mathrm{~mm} \mathrm{day}^{-1}$, respectively (mean $T+=0.78$ for R20S and 0.72 for R10S), whereas other indices performed relatively poorly, suggesting that the ability to hindcast flooding may be associated with some antecedent soil moisture conditions. We further explore this by using a process-based land surface model (TEM) to include soil moisture conditions (Fig. S4 of the online supplemental material). TEM is a prognostically based numerical model of biogeochemical processes between vegetation, soils, and the atmosphere (Felzer et al. 2009). Our results at selected sites indicate that AMC help to improve true-negative capture rates $(T-)$, and the pattern is consistent across sites and floodingrelated indices.

Comparisons between wet and dry factors and predictability with coefficient of variability (Table S3 of the online supplemental material) show the degree to which these indices are affected by precipitation variability and are discussed in section SI7 of the online supplemental material. Global patterns (Figs. S5-S9 of the online supplemental materia) are discussed in supplemental section SI8.

\section{Discussion and conclusions}

Our main goal was to see whether weather records might provide a sufficient substitute for ethnographically reported drought and flood hazards for societies in the ethnographic record. Accordingly, we compared a series of weather-derived indicators for our sample societies with known drought and flood dates. Our results 


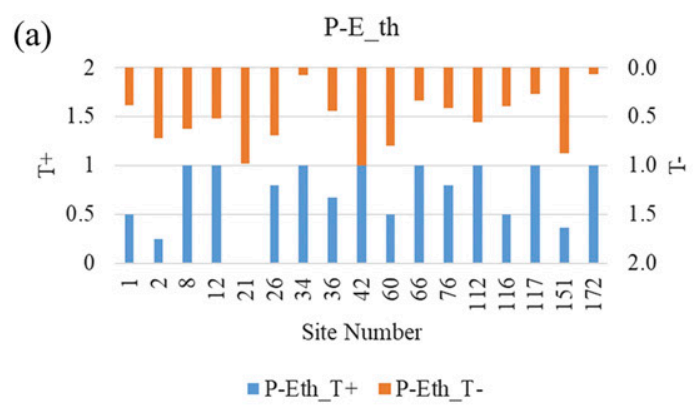

PDSI

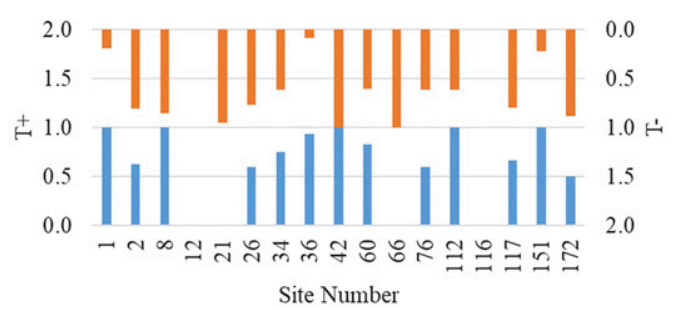

=PDSI_T+ $=$ PDSI_T-

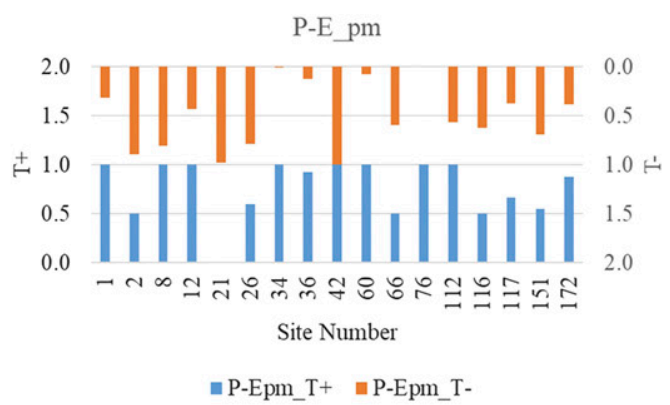

Combined Index

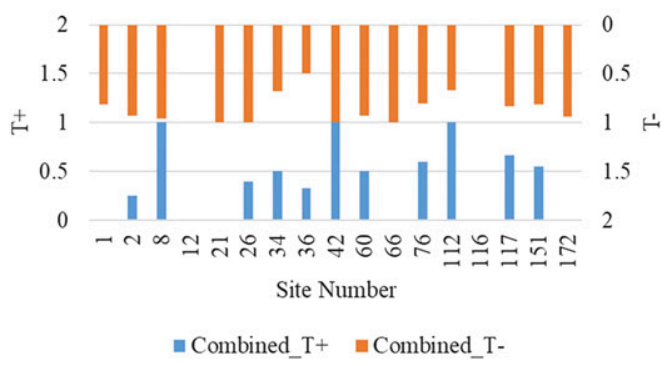

(b)

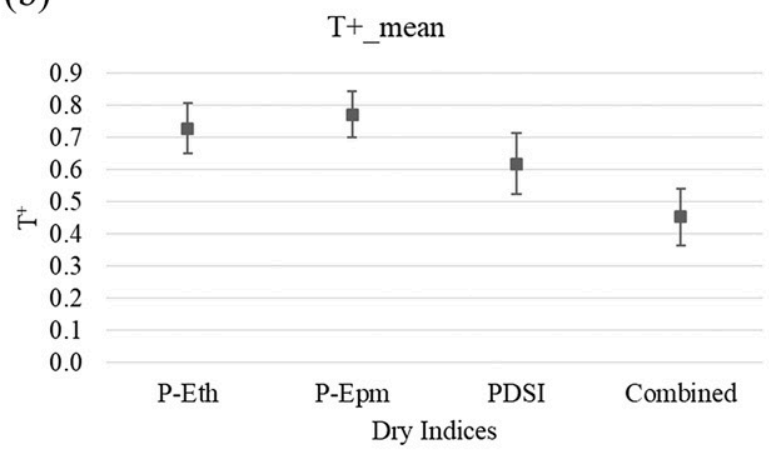

T-_mean

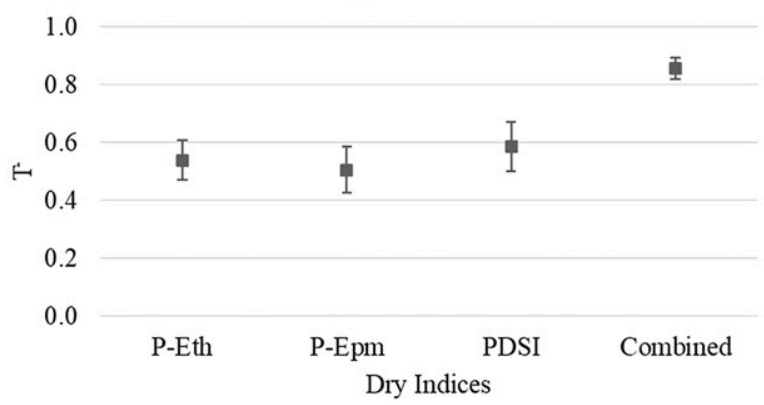

FIG. 4. (a) Drought results for true positives $(T+)$ and true negatives $(T-)$ for 17 sites and four drought indices based on gridded climate data ( $P-E_{-}$th, $P-E_{-}$pm, PDSI, and combined drought index of all three). The $T+$ and $T-$ values are in the range from 0 to 1 , with 1 indicating highest $T+$ and $T-$, respectively. (b) Mean drought results for $T+$ and $T-$ for $P-E_{-}$th, $P-E_{-}$pm, PDSI indices, R01, R05, and CDD indices. The error bars are standard errors.

show the limitations of using any one meteorological measure to hindcast ethnographic hazards. Some measures generally predicted the presence (or the absence) of drought or flood fairly well, but no measure predicted both well. In addition, our percentage accuracies are not as high as we would have liked. On the other hand, we find that using multiple measures did enhance the accuracy of hindcasting. 

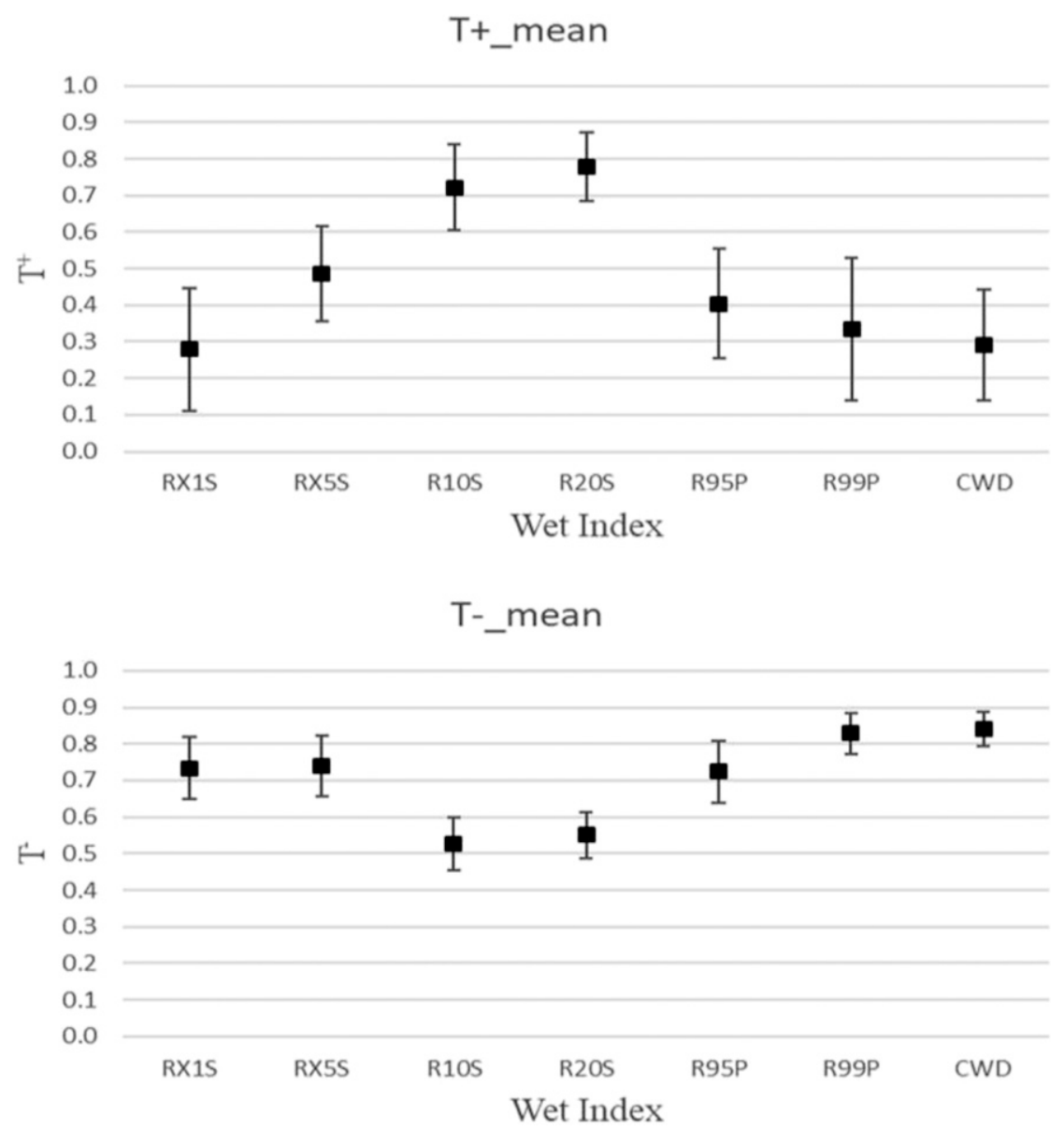

FIG. 5. Mean flood results for (top) $T+$ and (bottom) $T$ - for seven extreme precipitation indices. Error bars are standard errors. On the $y$ axis is the proportion of societies that were predicted correctly; on the $x$ axis are different wet indices.

The two best measures of hindcasting the ethnographically reported droughts were the $P-E$ measures ( $P-E_{-}$pm and $P-E_{-}$th $)$, which picked up $73 \%$ and $77 \%$, of the droughts $(T+)$, respectively. PDSI only picked up ethnographically reported droughts $62 \%$ of the time. On average, all three individual measures did worse on predicting the absence of drought $(51 \%-$ $59 \%$ ) as compared with the presence of drought (Fig. 4). This implies that using weather data tends to overpredict hazards relative to the ethnography. This discrepancy may be partially due to the fact that ethnographers likely note only the events that are remembered because they cause serious harm to food supplies, which suggests that they will underreport events that do not cause much harm. In addition, the seriousness of hazards is affected by social processes, including the presence of coping strategies and contingency plans. Also, ethnographers may underreport because they may not stay for more than a year or so, and they may not find adequate material to create a comprehensive history. However, we note that even when we have a better handle on the historical record, as in our examples of Pennsylvania and Oregon, the drought years do not always correspond to serious crop failure (supplemental Fig. S2). Irrigation is not a factor for maize in Pennsylvania, but a larger percentage of maize is irrigated in Oregon, so that practice could ameliorate drought effects in Oregon (USDA 2019).

Interestingly, we find that the combined drought measure, which is based on the three individual measures simultaneously predicting a drought occurrence (or the lack of all three concurring) in a particular year, performs well in predicting the absence of drought $(87 \%$ correctly: $T-$ ). The combined drought measure is very conservative and, although it gives us more confidence that it is predicting the lack of drought correctly, note that this measure does much worse $(42 \%)$ in predicting the presence of drought. In general, the higher the $T+$ is, the lower the $T$ - is and vice versa, because an index that picks up more drought or flood events will be 
more likely to predict the recorded event while also overpredicting other years that do not have recorded extreme events. We conclude that it is better to use both the combined drought measure to hindcast the absence of drought and the $P-E$ measures to hindcast the presence of drought.

Our efforts to predict flood with the best wet indices (R10S and R20S, which predicted correctly $72 \%$ and $78 \%$ of the time, respectively) fared similarly to the $P-E$ measures as predictors of flood; but, as we noted above, several indices had zero $T+$ capture rates for some sites (supplemental Fig. S3). This may be because our ethnographic data concentrated on hazards that destroy food supply and an overabundance of rain may have led to little or no crop failure. In general, it is found that droughts and extreme heat have a larger effect on crop yields than does heavy precipitation. Depending on landscape heterogeneity and catchment size, flood events, at least in the past, were generally highly localized and short-lived. Moreover, if flood events occur outside the growing season, they will have no effect on crop yields. At the national U.S. scale, for example, Lesk et al. (2016) found from 1964 to 2007 that droughts and extreme heat reduced crop yield by $9 \%-10 \%$ but that floods or extreme cold had no discernible effect. In sum, although not all droughts affect food supply, most likely do. However, extreme precipitation is not as closely tied to damage to food supply as drought is, in part because more moisture may actually help crops grow better, and flooding may be a localized, ephemeral event and may not occur in growing seasons.

Furthermore, wet extremes are not necessarily a good indicator of floods because they do not account for antecedent moisture conditions, which are a prerequisite for flood occurrence. The long-standing view in hydrology was that floods are the result of heavy rainfall on wet soils. While this concept is often true, research has shown that it is a limited view of the physical mechanisms that lead to flooding. For example, research on historical flood events has shown that rainfall amount is not the strongest predictor of flooding. Snowmelt, rain on snow, and precipitation in excess of soil moisture capacity were shown to be better predictors than rainfall amounts in the Model Parameter Estimation Experiment (MOPEX) basins across the United States (Berghuijs et al. 2016; T. Troy 2016, personal communication). Similarly, with AMC considered, here we demonstrated an improved true-negative capture rate $(T-)$ of flooding events (supplemental Fig. S4), highlighting the importance of connecting meteorological factors with surface water availability to make better predictions of flooding and the associated impacts to food supply.
Our extreme indices, condensed into one factor for each class of extremes using factor analysis (see supplemental section SI3), will be used in our subsequent research to explore how climate affected societies in the recent past and how societies adapt and respond to shortages in food supply. To the first order, extreme precipitation and temperature events are positively correlated with their corresponding precipitation and temperature patterns. Spatially, deviations from this general pattern are visible, with the extent of variation depending upon whether we use absolute or relative indices. Since during ENSO or other modes of climate variability there are generally more wet extremes (or fewer dry extremes) during wet phases and fewer wet extremes (or more dry extremes) during dry phases, the extreme indices themselves often offset each other over decadal time scales. Overall, there are generally fewer wet and dry extremes in more variable climates. Predictability shows spatially heterogeneous patterns, likely reflecting effects of climate, climate variability, and modes of large climate oscillation systems. In general terms, predictability is highest in arid regions with low year-round precipitation. Seasonality of extremes also matters concerning food supply. Most modes of climate variability are dominated by wintertime responses, whereas wet monsoons are summer phenomenon, and therefore more likely to affect crop yield. Overall, more dry or wet extremes usually correlate with lower dry and wet predictability.

How are these measures and indices useful? Given the worldwide availability of data, weather/climate measures can be constructed in a far shorter time and with broader world coverage than it would take to collect data from the historical and ethnographic records, if they are available. Thus, use of such indicators makes it more feasible to evaluate possible environmental effects on cultural beliefs, practices, and attitudes. Some previous research, particularly on moralizing high gods (supreme beings that are believed to render punishment to people for their transgressions) has suggested relationships between environmental variables and moralizing high gods. For example, Snarey (1996) found beliefs in moralizing high gods are more likely with water scarcity, and Botero et al. (2014) found that less climate stability (provided that the environment was not too resource poor) predicted such high gods. While our research is still ongoing, we are also finding that many of the indices, predictability measures, and factor scores we describe here also predict the beliefs that gods are associated with weather, sometimes helping with food supply and sometimes hurting food supply, even in the absence of moral punishment. Previous research using small samples of societies found that the 
frequency of food-destroying natural hazards strongly predicted more warfare in nonstate societies [Ember and Ember (1992a), with replication in eastern Africa (Ember et al. 2019)]; our new measures should allow us and others to examine relationships to warfare on larger samples. Ethnographically described natural hazards and other resource stressors predict more customary sharing of food and labor (Ember et al. 2018) in the sample described here. With more refined measures suggesting the type of natural hazard (e.g., drought or flood) and measures of predictability, we have an opportunity to expand the number of societies we can study and have more nuanced variables. Taken together, our indicators may provide a new approach for comparing different globally distributed ethnographically described societies so that we can use these measures to fill in the gaps in the ethnographic records or use them in future predictive analyses. The importance of this endeavor is that an increasing number of studies are using ethnographically described samples to try to better understand the impact of natural hazards and other environmental variables on culture in the recent past to better inform the present. In the future, this may help us and other researchers determine relationships between extreme events and societal response over longer time scales than otherwise available.

Acknowledgments. This material is based upon work supported by the National Science Foundation (NSF) Interdisciplinary Behavioral and Social Science (IBSS) under Grant 1416651 (program solicitation NSF 12-614). We acknowledge other members of our team-Peter Peregrine, Eric Jones, and Michele Gelfand-for their discussions and suggestions throughout this process. We also thank Rachele Pierro, Sarah Casson, Megan Ferrar, Tahlisa Brougham, Christina Carolus, and Emily Pitek for their assistance with finding dates of hazards and more precise locations for ethnographic sites. Christina Carolus in particular helped process the data on growing seasons and biomes. We also thank Aiguo Dai for providing the ENSO correlation coefficient data.

\section{REFERENCES}

Abdi, H., 2010: Coefficient of variation. Encyclopedia of Research Design, N. Salkind, Ed., Sage, https://doi.org/10.4135/ 9781412961288.

Alley, W. M., 1984: The Palmer drought severity index: Limitations and assumptions. J. Climate Appl. Meteor., 23, 1100-1109, https:// doi.org/10.1175/1520-0450(1984)023<1100:TPDSIL > 2.0.CO;2.

Berghuijs, W. R., R. A. Woods, C. J. Hutton, and M. Sivapalan, 2016: Dominant flood generating mechanisms across the United States. Geophys. Res. Lett., 43, 4382-4390, https:// doi.org/10.1002/2016GL068070.
Botero, C. A., B. Gardner, K. R. Kirby, J. Bulbulia, M. C. Gavin, and R. D. Gray, 2014: The ecology of religious beliefs. Proc. Natl. Acad. Sci. USA, 111, 16784-16789, https://doi.org/ 10.1073/pnas.1408701111.

Chang, K.-Y., L. Xu, and G. Starr, 2018: A drought indicator reflecting ecosystem responses to water availability: The normalized ecosystem drought index. Agric. For. Meteor., 250-251, 102-117, https://doi.org/10.1016/j.agrformet.2017. 12.001 .

Colwell, R. K., 1974: Predictability, constancy, and contingency of periodic phenomena. Ecology, 55, 1148-1153, https://doi.org/ 10.2307/1940366.

Ember, C. R., and M. Ember, 1992a: Resource unpredictability, mistrust, and war: A cross-cultural study. J. Conflict Resolut., 36, 242-262, https://doi.org/10.1177/0022002792036002002.

_, and _ 1992b: Warfare, aggression, and resource problems: Cross-cultural codes. Behav. Sci. Res., 26, 169-226, https:// doi.org/10.1177/106939719202600108.

—_, T. A. Adem, and I. Skoggard, 2013: Risk, uncertainty, and violence in eastern Africa: A cross-regional comparison. Hum. Nat., 24, 33-58, https://doi.org/10.1007/s12110012-9157-5.

, I. Skoggard, E. J. Ringen, and M. Farrer, 2018: Our better nature: Does resource stress predict beyond-household sharing? Evol. Hum. Behav., 39, 380-391, https://doi.org/10.1016/ j.evolhumbehav.2018.03.001.

—_, E. C. Jones, I. Skoggard, and T. A. Adem, 2019: Warfare, atrocities, and political participation: Eastern Africa. J. Aggression Conflict Peace Res., 11 (1), 11-23, https://doi.org/ 10.1108/JACPR-05-2017-0290.

Felzer, B. S., T. W. Cronin, J. M. Melillo, D. W. Kicklighter, and C. A. Schlosser, 2009: Importance of carbon-nitrogen interactions and ozone on ecosystem hydrology during the 21st century. J. Geophys. Res., 114, G01020, https://doi.org/10.1029/ 2008JG000826.

,,,,,----- and S. R. S. Dangal, 2011: Nitrogen effect on carbon-water coupling in forests, grasslands, and shrublands in the arid western U.S. J. Geophys. Res., 116, G03023, https://doi.org/10.1029/2010JG001621.

Harris, I., P. D. Jones, T. J. Osborn, and D. H. Lister, 2014: Updated high-resolution grids of monthly climatic observationsThe CRU TS3.10 dataset. Int. J. Climatol., 34, 623-642, https:// doi.org/10.1002/joc.3711.

Jiang, M., B. S. Felzer, and D. Sahagian, 2016: Characterizing predictability of precipitation means and extremes over the conterminous United States, 1949-2010. J. Climate, 29, 26212633, https://doi.org/10.1175/JCLI-D-15-0560.1.

Kang, B. W., 2000: A reconsideration of population pressure and warfare: a protohistoric Korean case. Curr. Anthropol., 41, 873-881, https://doi.org/10.1086/317416.

Karl, T. R., N. Nicholls, and A. Ghazi, 1999: CLIVAR/GCOS/WMO Workshop on Indices and Indicators for Climate Extremes workshop summary. Weather and Climate Extremes, Springer, 3-7, https://doi.org/10.1007/978-94-015-9265-9_2.

Köppen, W., and R. Geiger, 1936: Handbuch der Klimatologie (Handbook of Climatology). Vol. 1, Part C, Gebrüder Borntraeger, $44 \mathrm{pp}$.

Lesk, C., P. Rowhani, and N. Ramankutty, 2016: Influence of extreme weather disasters on global crop production. Nature, 529, 84-87, https://doi.org/10.1038/nature16467.

Menne, M. J., I. Durre, R. S. Vose, B. E. Gleason, and T. G. Houston, 2012: An overview of the Global Historical Climatology Network-Daily database. J. Atmos. Oceanic 
Technol., 29, 897-910, https://doi.org/10.1175/JTECH-D11-00103.1.

Murdock, G. P., and D. R. White, 1969: Standard cross-cultural sample. Ethnology, 8, 329-369, https://doi.org/10.2307/3772907.

NCEI, 2019: U.S. billion-dollar weather and climate disasters. NOAA, https://www.ncdc.noaa.gov/billions/.

Palmer, W., 1965: Meteorological drought. U.S. Department of Agriculture Weather Bureau Research Paper 45, 65 pp., https:// www.ncdc.noaa.gov/temp-and-precip/drought/docs/palmer.pdf.

Peterson, T., C. Folland, G. Gruza, W. Hogg, A. Mokssit, and N. Plummer, 2001: Report on the activities of the Working Group on Climate Change Detection and related rapporteurs. WMO Rep., 143 pp., http://etccdi.pacificclimate.org/ docs/wgccd.2001.pdf.

Sacks, W. J., D. Deryng, J. A. Foley, and N. Ramankutty, 2010: Crop planting dates: An analysis of global patterns. Global Ecol. Biogeogr., 19, 607-620, https://doi.org/10.1111/ j.1466-8238.2010.00551.x.

Snarey, J., 1996: The natural environment's impact upon religious ethics: A cross-cultural study. J. Sci. Study Relig., 35, 85-96, https://doi.org/10.2307/1387077.
USDA, 2019: Quick stats: Corn silage yield. USDA National Agricultural Statistics Service, accessed 11 November 2019, https://www.nass.usda.gov/Quick_Stats/.

van der Schrier, G., J. Barichivich, K. Briffa, and P. Jones, 2013: A scPDSI-based global data set of dry and wet spells for 19012009. J. Geophys. Res., 118, 4025-4048, https://doi.org/10.1002/ jgrd.50355.

White, D. R., 1989: Focused ethnographic bibliography: Standard Cross-Cultural Sample. Behav. Sci. Res., 23, 1-145, https:// doi.org/10.1177/106939718902300102.

Willmott, C. J., C. M. Rowe, and Y. Mintz, 1985: Climatology of the terrestrial seasonal water cycle. J. Climatol., 5, 589-606, https:// doi.org/10.1002/joc.3370050602.

Zhang, D. D., J. Zhang, H. F. Lee, and Y. He, 2007: Climate change and war frequency in Eastern China over the last millennium. Hum. Ecol., 35, 403-414, https://doi.org/10.1007/ s10745-007-9115-8.

- H. F. Lee, C. Wang, B. Li, Q. Pei, J. Zhang, and Y. An, 2011: The causality analysis of climate change and large-scale human crisis. Proc. Natl. Acad. Sci. USA, 108, 17 296-17301, https://doi.org/10.1073/pnas.1104268108. 